\title{
Commentary
}

\section{Agriculture in Pakistan: A Revisit}

\author{
MAHMOOD HASAN KHAN \\ Emeritus Professor of Economics, Simon Fraser University, Canada.
}

I started studying the structure and performance of Pakistan's agriculture in the early 1960s. Sadly this sector of the economy is still in a precarious state. I think the blame rests with the state, its policies and agents, more than the vagaries of nature. But the good news is that we can influence public policy far more than the moods of nature. The basic challenges for the agriculture sector in Pakistan are to:

- meet the changing consumer preferences and dietary habits induced by income growth and urbanisation;

- conserve land and water resources in the face of the not-too-certain but potentially serious consequences of climate change;

- absorb the rapidly rising cost of inputs (particularly energy) and maintain farm profitability;

- involve small farmers and livestock holders in a diversified and commercial agriculture;

- open new investment opportunities in the rural non-farm economy to provide jobs to the landless rural labour; and

- integrate into the global (and increasingly competitive) markets for food and industrial raw material.

But these challenges also offer new opportunities and incentives to make the agriculture sector a vibrant partner, if not leader, of the national economy. There are numerous policy issues given the multiple and competing interests of stakeholders, including small and large landowners and livestock holders, landless tenants and labourers, private market intermediaries (traders, processors and manufacturers), consumers, not-for-profit private organisations, and the public sector departments and agencies. I can identify four major policy issues.

(1) Productivity and quality of land and water resources.

(2) Production and distribution of crop seeds and livestock breeds.

(3) Transfer and adoption of productivity-enhancing and profitable technologybiotechnology in particular since it reduces dependence on input-intensive technology and protects the environment and quality of the resource base. 
(4) Market structures (supply chains) and government regulations for markets of fruits, vegetables and livestock and their products.

The policy framework that I suggest is premised on three propositions. First, we should use a 'farming systems' approach, in which crops and livestock are viewed as two interdependent parts of the production regime adapted to the changing resource endowment and markets. Second, small farmers (landowners and tenants) and livestock holders are the key players-small-scale agriculture supports the livelihoods of a majority of the rural poor-whose integration in the rapidlyexpanding commercialised agriculture is an essential part of the transformation process. Needless to add, the economic survival of small farmers depends on their livestock and wage labour. Third, the agencies of the state should be in the business of protecting property rights that are well defined; investing in public goods (infrastructure and support services); regulating the marketplace for quality and safety for producers and consumers; maintaining an efficient and fair regime of taxation; and providing support (safety-net) to the disadvantaged and vulnerable individuals or groups by income, gender, age, or skills. The business of state is not to throttle private initiative and innovation by myriad controls and distort the signals for efficient production and distribution of goods and services.

It is widely recognised that the average yield levels of crops and livestock products in Pakistan are far lower than what can be achieved. And the disposal of what is produced on the farm is based on an agriculture marketing system which tends to penalise both producers and consumers. In the context of designing and implementing policies for an inclusive and sustainable process of agricultural growth in Pakistan, it seems fair to take into account at least five conditions.

(1) It is essential that the national and provincial research systems produce, convert and adapt the best scientific knowledge that exists nationally and internationally.

(2) The stock of tested knowledge and technology should be transferred to farmers and holders of livestock in packages that raise the efficiency levels of their resources and farm profits: profitability of new technology is the ultimate test of how well it is adopted by ordinary farmers, given their conditions and resource constraints of ordinary farmers. Needless to add, farmers, no matter how small or resource-constrained, are quite receptive to profitable technology no matter where and how they happen to find it.

(3) Farmers should have an environment in which their rights to property and resources are well protected; they have fair access to well-regulated and competitive markets for buying farm inputs and services and sell their products; they are supported by the state - three levels of government and other agencies - with (a) good quality of physical and social infrastructure (public goods) and (b) macroeconomic policies and regulatory regimes that are well-designed for proper (non-distortionary) incentives and fairly enforced to maintain confidence. 
(4) Since a vast majority of farmers and livestock holders are small and they contribute a significantly large proportion of food and other agricultural products in the country, they should be provided fair access to resources and a plain (fair) playing field for participation in the marketplace. Their integration in the rapidly-growing commercial environment — there are good participatory models available for this purpose-will contribute not only to the well-being of these groups but also to other economic and social goals at the local, provincial and national level.

(5) Given the concern with issues of environmental degradation, food safety and health the world over and the more open and competitive international markets, it is absolutely essential to (i) wean the farmers away from dependence on input-intensive technology and wasteful management practices and (ii) put in place and enforce rules and regulations that maintain proper incentives for private initiative, innovation and investment, reduce space for rent-seeking and penalise perverse behaviour (pollution and free-riding). Price-distorting and inequitable (generalised) subsidies, which drain public resources with high opportunity cost, are not part of the emerging regime for international trade in agricultural goods. Government policy must shift from providing subsidies on farm inputs to investment and support for research and extension services, market infrastructure and information, electrification, and value-addition in crop and livestock products.

I should add three notes of caution here. First, on some issues the existing information is quite good but on others it is either incomplete or of uncertain quality. Some 'facts' (data) or propositions will have to be tested (researched) and validated to arrive at reasonable conclusions about change. Almost all of the statistics on economic and social indicators are produced by one or another government agency at the federal or provincial level. These agencies have almost unchallenged (if not unchallengeable) control of the information and data they possess. An associated and necessary aspect is the secrecy with which the monopolist protects the numbers (data) with impunity. In fact, it is secrecy that empowers the holders of information. A third reason is the dubious competence and lack of rigour with which the data are gathered, processed and disseminated.

Second, it is not a good idea to make drastic or large-scale changes of which the consequences are not well known or well tested on a small scale: do not through the baby away with the bath water! But this is not a signal to do nothing since the cost of doing nothing or procrastinating can be enormous if not disastrous. Suffice is to say that the power of vested interests (and special interest groups) to resist change should not be underestimated, especially in a predominantly patron-client social system.

Third, the issues discussed in this paper are limited in number and on each issue the focus is on only those aspects that are considered worth exploring for further research and action by policy-makers and their agents.

Let me now turn to what I consider are the important issues for public policy to improve the performance of agriculture in Pakistan. 


\section{Agricultural Land}

(1) Good farmland should be protected from its less agreeable alternative uses, especially around the periphery or in close proximity of the urban centres, by proper and enforceable zoning regulations.

(2) Legislate private right to the ownership of agricultural land and enter into official record the title of the legitimate owner. It is absolutely essential to involve all stakeholders in the land survey (using the GIS) needed to resolve the competing claims on land in the existing land record.

(3) It is important to find out why the pilot projects on the computerisation of land record have not produced the anticipated results. What lessons have been learnt? Once the digitised land record is completed, do away with the 'patwari' system in the provinces.

(4) Protection of land quality should be high on the policy agenda: change the distorted price signals and similar policies that encourage farmers to use the input-intensive technologies. We know that the zero tillage, green manuring, composting and crop rotation help improve the structure and fertility of soils.

\section{Irrigation Water}

(1) Put in place a regulatory framework for the use of groundwater and enforce the rules to avoid overexploitation of the aquifer. Why not vest the ownership of groundwater with the state and give fair access to individuals on demand.

(2) What lessons have been learnt from the farmer-controlled canal irrigation system and how they have been incorporated in the new canal command areas? How does the new system compare with the government-controlled centralised canal irrigation system?

(3) Introduce on a pilot basis a volume-based system of irrigation water supply starting at the tail-end of watercourses.

(4) Management of water at the farm level must be improved by testing and disseminating technologies that take into account the economic and technical constraints of farmers and the small farmers in particular. Are the small farmers too far behind the large farmers in the adoption process? What are the major reasons? How can their constraints be alleviated?

\section{Crop Varieties and Livestock Breeds}

Given the importance of good seeds for crops and their limited use, the regulatory framework should create incentives for breeders in the private and public sectors and private suppliers of seed (produced locally or imported) and regulate the quality and safety aspects of seeds available to farmers in the marketplace. Too many controls create plenty of room for perverse (rent-seeking) behaviour. Give incentives to the private sector to invest in the projects of breeding, feeding and veterinary services for livestock. Given the success of genetically-modified organisms in many countries, should we not focus the knowledge of biotechnology on crop varieties for higher yield levels, greater resistance to pests and weeds, better adaptation to climate change, and lower dependence 
on inputs and resources? In a similar way, this technology should be used to improve the breeds of animals for milk and meat.

\section{Agriculture Research and Extension Services}

(1) Since good research and extension services are important for the growth of a productive agriculture and farm income, and given the widespread doubts about the effectiveness of the existing agriculture research and extension services, it would be interesting to estimate the rate of return on public sector investment in these activities. Has the service been worth the public money spent on it?

(2) How can (or should) the universities, provincial research and extension establishments and the private sector improve their collaboration to develop synergies?

(3) The attempt to 'corporatise' the provincial research institutes should be done with great care because of the unresolved issues about the transfer of assets and liabilities and the selection of research staff.

(4) Is the bifurcated system of extension service in crops and livestock the best way to transmit new technologies and messages to the farmer? Should the extension system not transform itself into a specialised service given by both the public and private sectors? Should the system not use a localised adaptive-research method in which the service interacts with the farmer through focus groups (e.g. Farmer Field Schools or Village Organisations) served by skilled professionals with the support of teams of research specialists? Why not move to a digitised information system between specialists and farmers?

\section{Markets for Agriculture Products}

(1) The government's monopoly on markets (mandis) for agriculture produce (e.g. fruits and vegetables) should be terminated and the private sector be allowed to establish regulated markets to reduce the number of intermediaries and their margins. The government should concentrate on providing a fair playing field to the buyer and seller and regulate the quality, grades, and safety of the produce.

(2) A similar approach is needed in the selling and buying of live animals and slaughter of animals. Government should not own the mandis for live animals and abattoirs, but regulate them well: let the private sector do its business. In fact, the government should give material incentives and facilities to the livestock holders and private investors to develop livestock pockets in the rural areas where the animals are kept by millions of small livestock holders.

(3) Finally, governments should not be capping the price of milk or meat in the urban areas since it either raises the price, or reduces the supply, or encourages malpractices (adulteration, etc.).

\section{Information and Data}

(1) Since government agencies collect and keep almost all of the information and data related to various aspects of crops, livestock and irrigation, it is necessary 
to improve their quality by involving other stakeholders in the planning, designing and collection processes. Data verification should be a continuous process.

(2) Government should remove all legal and administrative barrier for access to information and data - make them available on demand - which are of public interest. 